\title{
BMJ Open Inequalities in avoidable hospitalisation in large urban areas: retrospective observational study in the metropolitan area of Milan
}

\author{
Benedetta Pongiglione (D , ${ }^{1}$ Aleksandra Torbica, ${ }^{1}$ Michael K Gusmano ${ }^{2,3}$
}

To cite: Pongiglione $B$, Torbica A, Gusmano MK. Inequalities in avoidable hospitalisation in large urban areas: retrospective observational study in the metropolitan area of Milan. BMJ Open 2020;10:e042424. doi:10.1136/ bmjopen-2020-042424

- Prepublication history and supplemental material for this paper is available online. To view these files, please visit the journal online (http://dx.doi org/10.1136/bmjopen-2020042424).

Received 04 July 2020 Revised 19 0ctober 2020 Accepted 04 December 2020

Check for updates

(c) Author(s) (or their employer(s)) 2020. Re-use permitted under CC BY-NC. No commercial re-use. See rights and permissions. Published by BMJ.

${ }^{1}$ Centre for Research on Health and Social Care Management (CERGAS), SDA Bocconi School of Management, Bocconi University, Milan, Italy

${ }^{2}$ Department of Health Behavior, Society, and Policy, Rutgers University, New Brunswick, New Jersey, USA

${ }^{3}$ The Hastings Center, Garrison, New York, USA

\section{Correspondence to} Dr Benedetta Pongiglione; benedetta.pongiglione@ unibocconi.it

\section{ABSTRACT}

Objective Significant inequalities in access to healthcare system exist between residents of world megacities, even if they have different healthcare systems. The aim of this study was to estimate avoidable hospitalisations in the metropolitan area of Milan (Italy) and explore inequalities in access to healthcare between patients and across their areas of residence.

Design Retrospective observational study.

Setting Public and accredited private hospitals in the metropolitan area of Milan. Data obtained from the hospital discharge database of the Italian Health Ministry.

Participants 472579 patients hospitalised for ambulatory care sensitive conditions and resident in the metropolitan area of Milan from 2005 to 2016.

Outcome measure Age-adjusted rates of avoidable hospitalisations; OR for hospital admissions with ambulatory care sensitive conditions.

Methods Age-adjusted rates of avoidable hospitalisations in the metropolitan area of Milan were estimated from 2005 to 2016 using direct standardisation. For the hospitalised population, multilevel logistic regression model with patient random effects was used to identify patients, hospitals and municipalities' characteristics associated with risk of avoidable hospitalisation in the period 2012-2016.

Results The rate of avoidable hospitalisation in Milan fell steadily between 2005 and 2016 from 16.6 to 10.5 per 1000 . Among the hospitalised population, the odds of being hospitalised with an ambulatory care sensitive condition was higher for male (OR 1.42, $95 \% \mathrm{Cl} 1.36$ to 1.48 ), older (OR 1.012, 95\% Cl 1.01 to 1.014 ), low-educated (elementary school vs degree OR $4.23,95 \% \mathrm{Cl} 3.72$ to 4.81 ) and single (vs married OR $2.08,95 \% \mathrm{Cl} 2.01$ to 2.16 ) patients with comorbidities (OR 1.47, $95 \% \mathrm{Cl} 1.38$ to 1.56); avoidable admissions were more frequent in public non-teaching hospitals while municipality's characteristics did not appear to be correlated with hospitalisation for ambulatory care sensitive conditions.

Conclusions The health system in metropolitan Milan has experienced a reduction in avoidable hospitalisations between 2005 and 2016, quite homogeneously across its 134 municipalities. The study design allowed to explore inequalities among the hospitalised population for which we found specific sociodemographic disadvantages.
Strengths and limitations of this study

- Italian hospital discharge records include patient's sociodemographic information that represents a unique asset to explore individual-level characteristics associated to avoidable hospitalisations.

- The work is part of the international project 'World Cities Project' that enables comparisons between large metropolitan settings of population health outcomes using standardised definition (ie, ambulatory care sensitive conditions) so to assess the performances of different healthcare systems.

- The study design relies on hospital discharge records, therefore individual-level characteristics associated to avoidable hospitalisations were studied among the hospitalised population.

- Intrametropolitan comparison was possible only across municipalities as the residence of patients is not available at a more detailed level. This limits the scope of the assessment of urban inequalities.

\section{INTRODUCTION}

The largest cities in the developed world all face unprecedented challenges: how to meet the needs of a population that lives longer with declining birth rates, and how to adapt municipal services and social welfare programmes that have long been premised on a demographic structure that is changing rapidly. These cities are centres of economic growth and finance, culture and media, sophisticated transportation systems and innovations of different kinds. They are renowned for their centres of excellence in medical care, top-ranking medical schools, institutes of biomedical research and public health infrastructure. Likewise, they attract some of the wealthiest as well as the poorest populations of their nations and are destinations for large immigrant communities from around the world, which exacerbates social and spatial inequalities and forces their healthcare systems to confront the challenge of glaring inequalities. At the same time, 
health status of residents in these world cities, on average, has been found to be the same or better than health status at national level. For example, older persons in Paris and New York live longer than their counterparts in the rest of their countries. ${ }^{1}$ World cities share many sociodemographic and economic characteristics, but their healthcare systems have different characteristics, therefore the populations of each megacity may share similar experiences but also face different barriers.

The World Cities Project is an international collaboration launched in $2000^{2}$ with the purpose of studying urban health. In particular, the project has investigated the influence of individual, neighbourhood and health system characteristics on the use of healthcare services and the health status, such as mortality amenable to medical care, ${ }^{34}$ infant mortality ${ }^{5}$ and the use of revascularisations among patients with heart disease. ${ }^{6}$ It focused, initially, on the largest cities of the Organisation for Economic Co-operation and Development (OECD): New York City, London, Paris and Tokyo. In recent years, it has also examined health and healthcare systems in Hong Kong, Moscow, New Delhi, São Paulo and Shanghai. ${ }^{7-9}$ Here, we expand the scope of the project studying inequalities in avoidable hospitalisation (AH), measured as hospital admissions for ambulatory care sensitive conditions (ACSC), within the metropolitan area of Milan (also called Province of Milan or Greater Milan), which is located in the Lombardy region, Northern Italy. Scholars in urban planning and urban political economy include Milan among cities categorised as 'world cities', which are all hubs in the global economy. ${ }^{10}$ Milan is considered the economic capital of Italy in terms of its gross domestic product (GDP) per capita which is close to the top $20 \%$ of the 327 OECD metropolitan areas; the health system of Milan's region is characterised by the coexistence of public and private providers, with an out-of-pocket household expenditure higher, in some cases double, than in other regions. ${ }^{11}$ The population of the metropolitan area of Milan includes more than 200000 foreigners, which are concentrated in neighbourhoods outside the centre of the city. ${ }^{12}$ The metropolitan area includes 134 municipalities ('comuni') that differ significantly in terms of their economy, environment and social structure. The quality of life in metropolitan Milan has increased, but suburban areas have not kept up with its pace, and the observed economic growth has not involved all areas, but it has rather been driven by the municipality of Milan. ${ }^{13}$

In addition to sharing a variety of economic and demographic characteristics with international metropolitan areas, Milan also offers an interesting case because Italy's national health system shares important similarities and differences with health systems in which other megacities are located. Like England, France and Japan-but unlike the USA-Italy offers universal health coverage through its National Health Service (NHS) and essential healthcare services are free at the point of service. Similarly, like these other nations, Italy has focused in recent years on improving care coordination and reducing hospitalisations by encouraging more appropriate use of community-based services. Yet, Italy's per capita healthcare spending is significantly lower than in these other countries and below the European Union average. Compared with other countries in Europe, a relatively high percentage of Italians report that they have unmet medical needs and access to care is particularly problematic for Italians with lower socioeconomic status and immigrants. ${ }^{14}$ In response to these challenges, Italy tried to encourage the use of community-based services to improve access to ambulatory care and the coordination of care among health and social care providers. At the same time, there are concerns that the Italian health system has not responded adequately to the country's increase in chronic illness, including the stark rise in obesity and rates of diabetes. ${ }^{15}$

This works intends to estimate trends in $\mathrm{AH}$ in the metropolitan area of Milan over the past decade and to use hospital discharge records (HDR) to assess if there are sociodemographic differences between patients admitted for ACSC and patients admitted for non-ACSC, considering both their individual and community-level characteristics.

\section{METHODS \\ Data}

To conduct the analysis, we used anonymised hospital records for each patient hospitalised in the metropolitan area of Milan for the years 2005-2016. We used data from all available years to describe trends in hospitalisations for ambulatory sensitive conditions and restricted the analytical part to more recent years, 2012-2016, as explained below. The HDRs ('Scheda di dimissione ospedaliera') are the mean through which the Italian Health Ministry collects information on all admissions in public hospitals and private hospitals financed by the regional NHS (called accredited private). In case of repeated admissions over time, patients are tracked though their fiscal code and therefore their hospital path can be followed up.

HDRs include information about primary and secondary diagnoses, treatments, date of admission and discharge, length of stay and the address of the hospital where the patient was treated. Diagnoses and interventions are coded using the International Classification of Diseases Ninth Revision (ICD-9) Clinical Modification. The database also includes information about each patient's age, gender, citizenship status, educational attainment and home address, which is available only as municipality of residence. Using residence address, we were also able to calculate and include distance to the nearest hospital in kilometres in the model, approximated as distance from municipality of residence and municipality of the hospital, hence being zero when the two coincide. The inclusion of educational attainment, marital and citizenship status at the individual level is quite a unique feature for a hospital administrative database, not often available 
in similar data sources from other OECD countries. While this represents a strength of the study and a unique opportunity to explore the role of individual-level socioeconomic characteristics, it must also be considered that the quality of such information has been reported not to be high. ${ }^{16}$

From the HDRs, we were also able to include basic information on the admission hospital, including whether the hospital was public, accredited private or a teaching hospital, and the total number of ordinary and day hospital admissions per year in the hospital, as a proxy of hospital's size.

In addition to the individual-level data, we included information on the municipality of residence collected from the Italian National Statistics Institute, the Health Ministry and Ministry of Economy and Finance, and the Lombardy region database. These variables include average household size, proportion of foreigners among the resident population, proportions of residents aged under 6 , aged 50-64, 65-74 and above 75 years, proportion of residents with high school degree, percentage of voters at last local elections, proportion of residents below poverty threshold, which was defined using the income-based definition of relative poverty provided by the Banca d'Italia according to which those earning an income equal to or below $60 \%$ of the median national income are considered living below poverty threshold, and number of hospital beds per 100000 inhabitants in each municipality.

\section{Definition of AH}

Hospitalisations for so-called ACSCs are a valid indicator of access to timely and effective disease prevention and primary care services that reduce the probability of hospitalisation for medical conditions treated more effectively outside the hospital setting-before flare-ups leading to hospital admission. ${ }^{17-19}$ These include inpatient hospitalisations for pneumonia (with infection), cellulitis and several chronic conditions, such as congestive heart failure, asthma and diabetes with short-term complications. The rationale for focusing on ACSC is that if patients have access to timely and effective ambulatory care, it should be possible to reduce hospitalisations for these conditions by preventing the occurrence of the disease (eg, bacterial pneumonia) or managing the chronic condition in an outpatient setting (eg, asthma, arterial hypertension, diabetes, congestive heart failure). Such policies are based on evidence that high rates of ACSC hospitalisations reflect poor access to effective ambulatory care. ${ }^{172021}$ Weissman and colleagues ${ }^{22}$ conducted a literature review on ACSC and selected 12 hospital discharge diagnoses, using a panel of internists, for which variations in hospitalisation rates can be attributed to poor access to ambulatory care. Billings and Weinick identified a more extensive group of hospital stays, by principal discharge diagnoses, which they defined as 'avoidable' if patients receive timely and effective ambulatory care. ${ }^{23}$ Although patients with higher morbidity are routinely found to be at greater risk of being hospitalised for ACSC, ${ }^{24}{ }^{25}$ there is evidence of an independent effect of better access to ambulatory care on rates of hospitalisation for ACSC. ${ }^{26} 27$ After adjustments for different measures of health status, most studies support the conclusion that although hospital discharges for ACSC may reflect morbidity and health-seeking behaviours, there is international evidence in support of hospitalisations for ACSC as a measure of access to timely and effective ambulatory care in Australia, ${ }^{28}$ Canada, ${ }^{29}$ England, ${ }^{30}$ France, ${ }^{18}$ Italy $^{31-33}$ and many other countries.

We use a modified list of indicators that make up the definition of ACSC from the US Agency for Research and Quality. ${ }^{34}$ This definition includes hospitalisations for diabetes with short-term and long-term complications, perforated appendix, chronic obstructive pulmonary disease or asthma in older adults, hypertension, heart failure, dehydration, bacterial pneumonia, urinary tract infection, angina without procedure, uncontrolled diabetes and lower extremity amputation among patients with diabetes. The full list of conditions and corresponding ICD-9 codes is available in the online supplemental appendix table A1.

\section{Population of interest}

The description of hospitalisation trends is based on the number of ACSC admissions in the metropolitan area of Milan on the total resident population, and the total number of hospital admissions in the metropolitan area of Milan on the total resident population. For the second part of the study, where we considered sociodemographic characteristics of patients admitted for ACSC, the reference population are hospitalised residents of the metropolitan area of Milan, and therefore we compared patients admitted for ACSC with those admitted for non-ACSC.

\section{Statistical analysis}

To describe trends in ACSC we produced age-standardised rates considering the number of admissions for ACSC of patients resident in the metropolitan area of Milan, for each year, and the total resident population, and we used direct standardisation methods considering the Italian population in 2011 as a reference.

To study the factors associated with the probability of being hospitalised for an ACSC, we restricted the observation period to the most recent years (2012-2016) to avoid external noises deriving from the changes in the boundaries of the administrative units in 2009. We ran a mixed model with random intercept at the patient level $\log \left(\frac{\pi_{i j}}{1-\pi_{i j}}\right)=\beta_{0}+\beta_{1}^{\prime} X_{i j}+u_{j}$, for $j=1 \ldots \ldots . M$ clusters (patients), with cluster $j$ consisting of $i=1 \ldots \ldots n_{j}$ observations (number of admissions). After adjustment for fixed effects (including time), the random effects model accounts for residual correlation at the cluster level. We used a clustered sandwich estimator, estimating SEs allowing for intragroup correlation at the municipality level. $^{35}$ 
We discharged patients that changed residency (ie, municipality) from one admission to another to avoid complexity descending from dealing with not-nested clusters ( $\mathrm{n}=22780,1 \%$ of total sample). Online supplemental appendix figure A1 illustrates the analytical sample selection process via Strengthening the Reporting of Observational Studies in Epidemiology (STROBE) flow chart. The model included patient-level, hospital-level and district-level variables as described above. We used the interclass correlation (ICC) to quantify the proportion of variation in $\mathrm{AH}$ that was attributable to patients after adjustment for all level characteristics. When we ran the multilevel model, we introduced patient and municipalitylevel characteristics in a stepwise fashion. Results of the model including all covariates are reported in the Results section; results from previous steps are shown in the online supplemental appendix table A2. All analyses were performed using Stata V.16 (codes reported in the online supplemental appendix).

\section{Sensitivity analysis}

To deal with some data limitations, we performed several sensitivity analyses. First, given the low quality reported for marital status and education information and their high missing values which amount to around $40 \%$ taken together, we run a model with a version of both variables including a category for not declared and missing response, on a random subsample, given that the size of original data set did not allow calculation. Another limitation of the data is that the residence of patients is available only as municipality; Milan is much larger and heterogeneous compared with all other districts and it is not possible to identify any smaller area, for example, distinguishing the city centre and suburbs. Hence, we replicated our model excluding patients residing in municipality of Milan to see if the estimates at patient and municipality levels change compared with those obtained in the main model.

Finally, the complicated nature and large size of the data set, with unbalanced repeated measures (ie, number of readmissions ranged from 0 for 469039 patients to 76 for 1 patient) clustered within municipalities, prevented to implement a three-level model with patient and municipality random effects due to convergence problems. To assess whether the choice of the main model was robust, we also run a two-level model with municipality random intercept, $\quad \log \left(\frac{\pi_{i j}}{1-\pi_{i j}}\right)=\beta_{0}+\beta_{1}^{\prime} X_{i j}+u_{j}, \quad$ for $\quad j=1 \ldots \ldots . M$ (municipalities), with cluster $j$ consisting of $i=1 \ldots \ldots n_{j}$ observations (patients), ignoring the correlation between repeated admissions.

\section{Patient and public involvement}

This research was done without patient involvement. Patients were not invited to comment on the study design and were not consulted to develop patient-relevant outcomes or interpret the results. Patients were not invited to contribute to the writing or editing of this document for readability or accuracy.

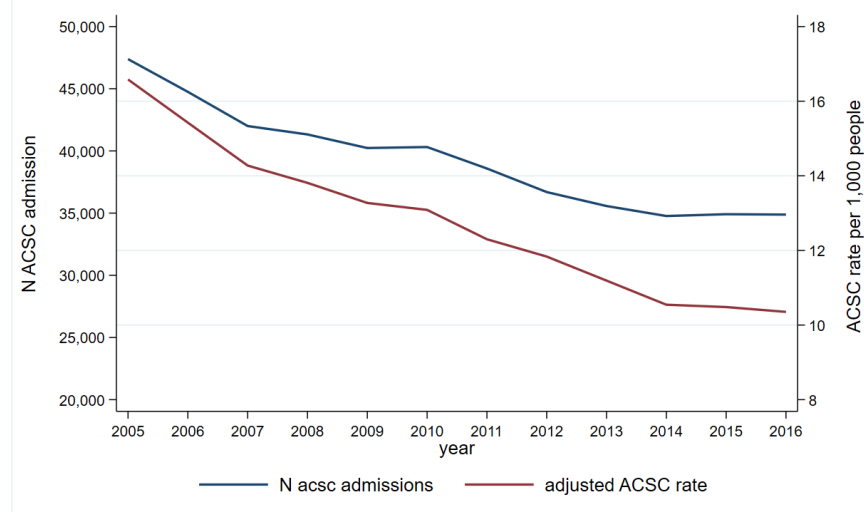

Figure 1 Age-adjusted rates and number of admissions for ambulatory care sensitive condition (ACSC) hospitalisation in metropolitan area of Milan from 2005 to 2016.

\section{RESULTS}

\section{Trends in ACSC hospitalisation}

Between 2005 and 2016, a total of 5671152 hospital admissions were recorded among the residents of the metropolitan area of Milan; of these, 472579 (around $8.3 \%$ ) were related to ambulatory sensitive conditions. Over the decade, both the age-standardised rate and the absolute number of hospital discharges declined: former fell by about $35 \%$ from 16.6 to 10.5 per 1000 (figure 1); the annual number of hospitalisations for ACSC also fell by about $26.4 \%$ from 47384 to 34884 hospital discharges.

Figure 2 shows the age-standardised rates for each municipality in 2012 and 2016. The comparison of single districts shows that the decline in $\mathrm{AH}$ was experienced by most units of the metropolitan area and does not suggest a geographical pattern in prevalence of $\mathrm{AH}$; the municipality of Milan, the largest area of the map, presented in both periods an intermediate rate.

\section{Analysis of hospitalised patients}

Table 1 presents the descriptive statistics of the patients admitted for ACSCs and non-ACSCs, considering their characteristics as measured at the first admission recorded in the study's time interval. Around $8 \%$ of total admissions were for ACSCs. Patients with ACSC were more often male, older, had almost twice as many comorbidities as patients without ACSC, had lower education level

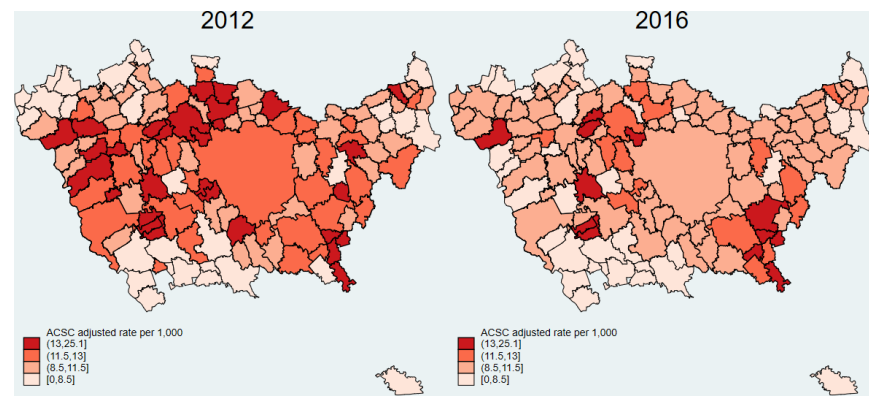

Figure 2 Age-adjusted rates of avoidable hospitalisation in metropolitan area of Milan in 2012 and 2016, by municipality. ACSC, ambulatory care sensitive condition. 


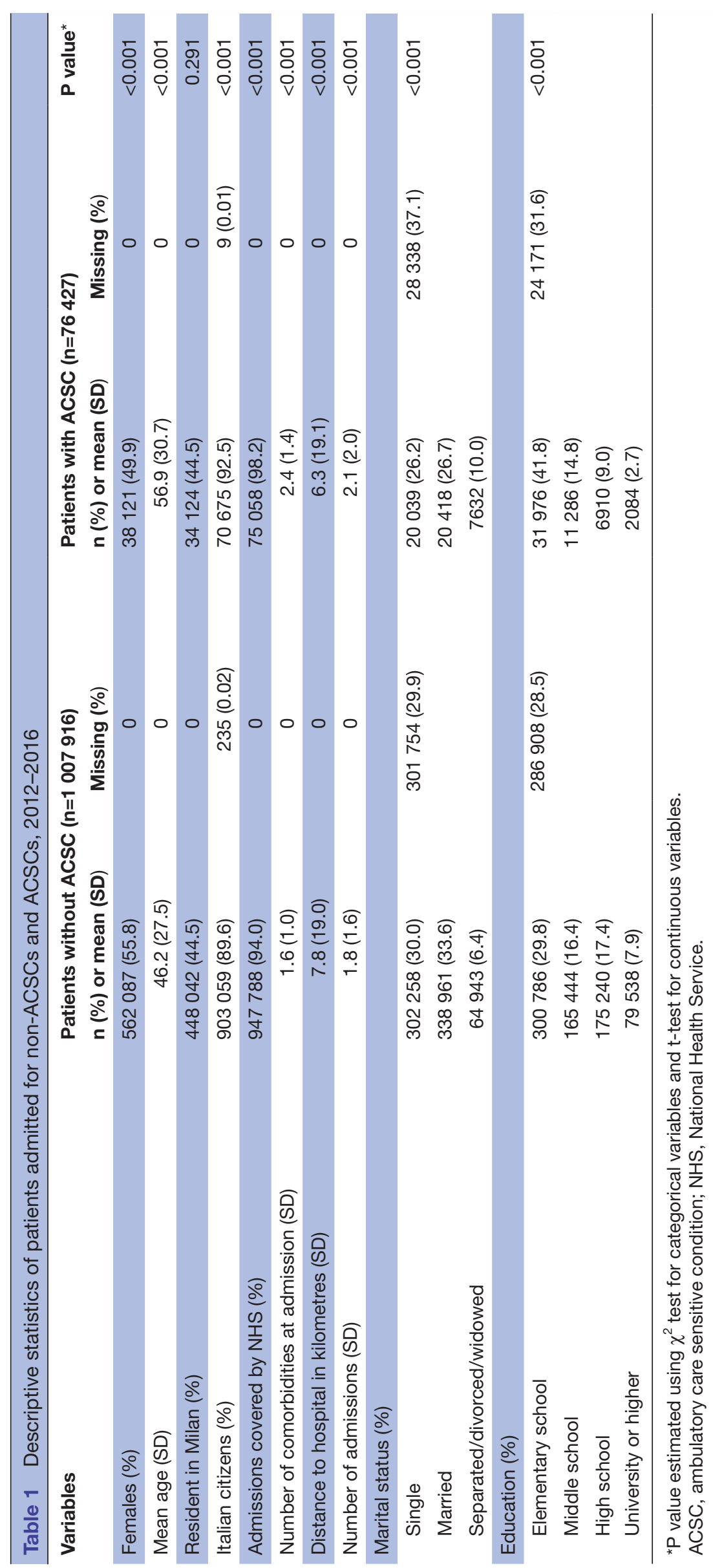


Table 2 ORs of ACSC hospitalisation from logistic random intercept model

\begin{tabular}{|c|c|c|c|}
\hline & OR & $P$ value & $95 \% \mathrm{Cl}$ \\
\hline Male & 1.420 & $<0.001$ & (1.358 to 1.484$)$ \\
\hline Age in years & 1.012 & $<0.001$ & (1.010 to 1.014$)$ \\
\hline Elementary school (vs higher degree) & 4.230 & $<0.001$ & (3.724 to 4.805$)$ \\
\hline Middle school (vs higher degree) & 2.014 & $<0.001$ & (1.916 to 2.117$)$ \\
\hline High school (vs higher degree) & 1.318 & $<0.001$ & (1.224 to 1.420$)$ \\
\hline Milan (vs other district) & 0.757 & 0.844 & (0.047 to 12.124$)$ \\
\hline Italian citizenship (yes vs no) & 1.084 & 0.001 & (1.034 to 1.136$)$ \\
\hline Paid by NHS (yes vs no) & 1.998 & $<0.001$ & (1.897 to 2.104$)$ \\
\hline Marital status single (vs married) & 2.083 & $<0.001$ & (2.014 to 2.155$)$ \\
\hline Marital status widowed/divorced (vs married) & 1.460 & $<0.001$ & (1.376 to 1.548$)$ \\
\hline Number of diagnoses & 1.468 & $<0.001$ & (1.382 to 1.559$)$ \\
\hline Number of admissions & 1.066 & $<0.001$ & (1.061 to 1.071$)$ \\
\hline Distance to hospital in kilometres & 0.996 & 0.376 & (0.987 to 1.005$)$ \\
\hline 2013 (vs 2012) & 1.102 & $<0.001$ & (1.056 to 1.149$)$ \\
\hline 2014 (vs 2012) & 1.15 & $<0.001$ & (1.084 to 1.221$)$ \\
\hline 2015 (vs 2012) & 1.237 & $<0.001$ & (1.132 to 1.351$)$ \\
\hline 2016 (vs 2012) & 1.359 & $<0.001$ & (1.242 to 1.488$)$ \\
\hline Number of ordinary admissions & 1.000 & 0.788 & (1.000 to 1.000$)$ \\
\hline Number of day hospital admissions & 1.000 & 0.313 & (1.000 to 1.000$)$ \\
\hline Private (vs public) & 0.425 & $<0.001$ & (0.364 to 0.496$)$ \\
\hline Teaching (vs public) & 0.629 & $<0.001$ & (0.583 to 0.679$)$ \\
\hline Hospital beds & 1.000 & 0.895 & (1.000 to 1.000$)$ \\
\hline Household size & 0.642 & 0.071 & (0.396 to 1.038$)$ \\
\hline$\%$ voters latest election & 1.005 & 0.07 & (1.000 to 1.010$)$ \\
\hline$\%$ with high school & 1.004 & 0.34 & (0.995 to 1.014$)$ \\
\hline$\%$ foreigners & 1.015 & 0.021 & (1.002 to 1.028$)$ \\
\hline$\%$ under 6 & 1.015 & 0.807 & (0.902 to 1.142$)$ \\
\hline$\%$ aged $50-64$ & 1.000 & 0.981 & (0.963 to 1.040$)$ \\
\hline$\%$ aged $65-74$ & 1.052 & 0.123 & (0.986 to 1.122$)$ \\
\hline$\%$ aged $75+$ & 0.946 & $<0.001$ & (0.920 to 0.973$)$ \\
\hline$\%$ under poverty threshold & 0.997 & 0.848 & (0.967 to 1.028$)$ \\
\hline Random effects & Variance & SE & $95 \% \mathrm{Cl}$ \\
\hline Patient & 2.802 & 0.194 & (2.447 to 3.208 ) \\
\hline Observation & 1115102 & & \\
\hline Number of groups & 690671 & & \\
\hline
\end{tabular}

ACSC, ambulatory care sensitive condition; NHS, National Health Service.

and a lower proportion was married. As anticipated, a very large proportion of patients do not have information on marital status and education, especially in the ACSC group.

Table 2 reports the ORs for each covariate (covariate's category) that express the odds of being hospitalised for ACSCs among the hospitalised individuals in the metropolitan area of Milan. Results are in line with those of previous studies, and suggest that male, older patients and patients with a higher number of diagnoses at the time of admission have greater odds of being hospitalised for ACSCs. The data used in this study also allow to observe that the odds of $\mathrm{AH}$ is higher for patients with lower levels of education and for single patients compared with those with any other family marital status. Patients who reside in Milan municipality have a lower risk of ACSC hospitalisation compared with those living in other districts (online supplemental appendix table A2), but once we account for the full set of controls the significance of association disappears; $\mathrm{AH}$ is also much more likely for patients whose 
admission is fully covered by the NHS. We also observe that ACSC hospitalisations are more common in public and no teaching hospitals compared with teaching hospitals as well as private hospitals. The characteristics of the patient's district of residence do not seem to be related with the odds of being hospitalised for ACSCs, it only emerged that those living in municipalities with a higher proportion of foreigners have a slightly higher odds of being hospitalised for an ACSC, but the magnitude of the association is very small (OR 1.015, $\mathrm{p}=0.021)$, and the finding is not consistent across model specifications.

The proportion of variation in ACSC hospitalisations that was attributable to individuals after adjustment for patient, hospital and municipality-specific characteristics was around $46 \%$ (ICC $=0.460,95 \%$ CI 0.427 to 0.494 ).

\section{DISCUSSION}

Hospitalisations for ACSC have become a widely used indicator of health system performance. Specifically, they are used to assess the degree to which people have timely access to effective ambulatory care that can manage illness and reduce the need for hospital admissions.

At the beginning of the study period, the rate was comparable to the rate observed in many US cities, which were among the highest in the OECD. By 2016, it was slightly higher than the rate in London, a comparable world city within an NHS. Understanding to what this reduction can be attributed is fundamental and goes beyond the purpose and means of this study. Here, we report some speculative considerations. Although the health status in Italy appears to be better than in many other European countries according to several measures, such as life expectancy, Italian population has experienced an increase in chronic illness during the past few decades ${ }^{36}$ also due to population ageing. Therefore, it is unlikely that the reduction in these hospitalisations is due to improvements in the population's health. It is possible that recent efforts to improve care coordination may help explain our results. For example, Italy is one of five countries in Europe that requires patients to register with a regular primary care provider who serves as a gatekeeper for referrals. ${ }^{15}$ A recent study in the neighbouring city of Parma found that the increases in the use of 'medical homes' led to a reduction in hospitalisations for ACSC. ${ }^{37}$ On the other hand, over the past two decades, hence during the observation interval, AHs and total hospitalisations decreased and for the latter the decline was even sharper (33\% compared with $26 \%$ ). Our results are in line with previous research on Italy that found very similar proportion of hospital admissions for ACSCs on total hospitalisations (8\%) in the period 2001-2008, as well as a decline in the overall rate of hospitalisation, but slower (equal to $19.6 \%$, and to $16.4 \%$ for hospitalisation for avoidable conditions).$^{32}$ Moreover, in the past decades, reduction has characterised not only hospitalisations: the number of hospitals has declined due to reconversion or merger of hospital units, and this mostly concerned public hospitals; NHS hospital beds were 350242 in 1997 and dropped to 210026 in $2017 .{ }^{38}$ From 2010 to 2018 the share of public healthcare expenditure on GDP declined from $7.0 \%$ to $6.5 \%$ (OECD data). Further research is needed to corroborate with empirical evidence the interpretation of existing evidence and macrodata.

The second contribution of our research was to assess whether there were differences between patients admitted to hospital for ACSC and those admitted for non-ACSC within metropolitan Milan. We found evidence of remarkable disparities. Several patients' characteristics were related to ACSC hospitalisation, in agreement with previous studies: men, older people and people with comorbidities were more likely to be hospitalised for these conditions. Patients having Italian citizenship had higher chance of ACSC hospitalisation compared with foreign patients; this finding is different from the results of most literature. However, a study of the Italian Network of Longitudinal Metropolitan Studies, a multicentre and multipurpose pool of metropolitan population cohorts enrolled in nine Italian cities not including Milan, found that $\mathrm{AH}$ rates for diabetes mellitus of adults from high migratory pressure countries had higher AH rates compared with Italians in every city, with the exception of Rome. ${ }^{39}$ This suggests that heterogeneity of findings may occur even within the same country and local context is very important.

A novel finding descends from the availability of information on education and marital status at the individual level. We found that the odds of $\mathrm{AH}$ was higher among low-educated patients compared with higher educated, and lowest among married patients. While the result is expected, it represents a unique contribution that the Italian administrative data allow to make by including such important socioeconomic indicators. At the same time, however, missingness and misreport of such variables are a serious limitation. For this reason, we performed a sensitivity analysis including the response 'not declared' and missing response on a random subsample (online supplemental appendix table A3). The coefficient estimates of all variables included in the full model remain almost unchanged, lowest educated and single remain the categories at highest risk of $\mathrm{AH}$, even compared with not reporting the information. The fact that widowed, separated and divorced are at lower risk than single accounting for age is not straightforward to interpret. It may be suggestive that they have other family ties, such as children, that facilitate access to healthcare and better health, but data do not permit to go beyond speculations. The identification of characteristics of individuals that face barriers to the appropriate use of ambulatory care that are not being addressed as well as possible has important implications. This can anticipate the need for more effective outreach to targeted populations.

We also considered municipality-level characteristics and we did not find any significant predictors of ACSC hospitalisation; only the proportion of foreigners living in patient's municipality was associated with $1.5 \%$ higher 
odds of ACSC hospitalisation compared with patients without ACSC $(p=0.021)$. A possible interpretation of this finding is that this indicator is a proxy for socioeconomic conditions of a municipality, more informative than poverty threshold and likely it captures more accurately the barriers to healthcare that a municipality may have. However, when we implemented another model specification with municipality random intercept (online supplemental appendix table A4) and ignoring that some observations belong to same patients, we found the association in the opposite direction (OR 0.984, $\mathrm{p}=0.076$ ).

Another anticipated limitation of the study is that the HDR data allow to consider patients' residence in no more depth than their municipality. Therefore, the municipality of Milan that is populated by 1.3 million inhabitants, about $40 \%$ of the total population of the metropolitan area, is counted as a single unit, and it is not possible to distinguish its neighbourhood that indeed has different socioeconomic, demographic and cultural characteristics. As a sensitivity analysis, we replicated the full model excluding patients resident in Milan (online supplemental appendix table A5), to consider cluster more homogeneous in terms of their size, and found almost no difference.

Finally, we do not cluster patients based on the admittance hospital, but it is important to note that we observed a strong correlation between the type of hospital and the chance of being admitted for ACSCs, with public not teaching hospitals more likely to admit patients for ACSC, while their size does not seem to matter.

All combined, results indicate a declining trend in $\mathrm{AH}$ and remarkable socioeconomic differences between patients admitted for ACSC and non-ACSC. Unfortunately, the study design does not allow to generalise such finding to the general population of the metropolitan area of Milan and so identify the individuals that are facing barriers to access primary healthcare. Nevertheless, results are suggestive of the existence of important inequalities that must be considered in a context of declining hospitalisations and reduction of resources of the healthcare system nationwide as well as in the economic capital of Italy.

Twitter Benedetta Pongiglione @benedettapongi, Aleksandra Torbica @ATorbica and Michael K Gusmano@gusmano_mk

Contributors MKG, AT and BP conceived and designed the study. MKG wrote the first draft of the manuscript and $\mathrm{BP}$ wrote the subsequent versions with support from AT. All authors had full access to all the data in the study and take responsibility for the integrity of the data. BP did the data analysis. All authors provided critical revisions to the manuscript and approved the final draft. BP is the guarantor of the study.

Funding The authors have not declared a specific grant for this research from any funding agency in the public, commercial or not-for-profit sectors.

Map disclaimer The depiction of boundaries on the map(s) in this article does not imply the expression of any opinion whatsoever on the part of BMJ (or any member of its group) concerning the legal status of any country, territory, jurisdiction or area or of its authorities. The map(s) are provided without any warranty of any kind, either express or implied.

Competing interests None declared.
Patient consent for publication Not required.

Ethics approval The current regulations of ethics committees in Italy require only standard written informed consent at the time of hospital admission and anonymous publication of scientific data. Our retrospective observational study fulfilled these requirements and was based on anonymised and deidentified hospital records.

Provenance and peer review Not commissioned; externally peer reviewed.

Data availability statement Data may be obtained from a third party and are not publicly available. Data were obtained from the hospital discharge database of the Italian Health Ministry. Statistical code will be made available upon request.

Supplemental material This content has been supplied by the author(s). It has not been vetted by BMJ Publishing Group Limited (BMJ) and may not have been peer-reviewed. Any opinions or recommendations discussed are solely those of the author(s) and are not endorsed by BMJ. BMJ disclaims all liability and responsibility arising from any reliance placed on the content. Where the content includes any translated material, BMJ does not warrant the accuracy and reliability of the translations (including but not limited to local regulations, clinical guidelines, terminology, drug names and drug dosages), and is not responsible for any error and/or omissions arising from translation and adaptation or otherwise.

Open access This is an open access article distributed in accordance with the Creative Commons Attribution Non Commercial (CC BY-NC 4.0) license, which permits others to distribute, remix, adapt, build upon this work non-commercially, and license their derivative works on different terms, provided the original work is properly cited, appropriate credit is given, any changes made indicated, and the use is non-commercial. See: http://creativecommons.org/licenses/by-nc/4.0/.

ORCID iD

Benedetta Pongiglione http://orcid.org/0000-0001-8539-1554

\section{REFERENCES}

1 Rodwin V. Growing older in world cities. New York, London, Paris, and Tokyo: Vanderbilt University Press, 2006.

2 Rodwin VG, Gusmano MK. The world cities project: rationale, organization, and design for comparison of megacity health systems. J Urban Health 2002;79:445-63.

3 Gusmano MK, Rodwin VG, Wang C, et al. Shanghai rising: health improvements as measured by avoidable mortality since 2000. Int $J$ Health Policy Manag 2015;4:7-12.

4 Weisz D, Gusmano MK, Rodwin VG, et al. Population health and the health system: a comparative analysis of avoidable mortality in three nations and their world cities. Eur J Public Health 2008;18:166-72.

5 Rodwin VG, Neuberg LG. Infant mortality and income in 4 world cities: new York, London, Paris, and Tokyo. Am J Public Health 2005;95:86-90.

6 Gusmano MK, Rodwin VG, Weisz D, et al. A new approach to the comparative analysis of health systems: invasive treatment for heart disease in the US, France, and their two world cities. Health Econ Policy Law 2007;2:73-92.

7 Gusmano MK, Rodwin VG, Weisz D. Delhi's health system exceptionalism: inadequate progress for a global capital City. Public Health 2017; 145:23-9.

8 Gusmano MK, Rodwin VG, Weisz D, et al. Health improvements in bric cities: Moscow, São Paulo, and Shanghai, 2000-10. World Med Health Policy 2016;8:127-38.

9 Chau PH, Woo J, Chan KC, et al. Avoidable mortality pattern in a Chinese population--Hong Kong, China. Eur J Public Health 2011;21:215-20.

10 Taylor PJ, Catalano G, Walker DRF. Measurement of the world City network. Urban Stud 2002;39:2367-76.

11 Longo F, Ricci A, Armeni P, et al. 10 key facts to understand the Italian healthcare system. CERGAS Bocconi University, 2018.

12 Rimoldi S, Terzera L. Ethnic segregation of foreign immigrants in Milan, 2012.

13 Uberti Foppa M. La città che cambia:Nuove disuguaglianze centroperiferia. Il caso di Milano [MSc Thesis], https://www.politesi.polimi. it/handle/10589/147960. 2019.

14 Glorioso V, Subramanian SV. Equity in access to health care services in Italy. Health Serv Res 2014;49:950-70.

15 Berchet C, Forde I. Caring for quality in health. OECD Publishing, 2017.

16 DG health planning. Programmazione Sanitaria Ministero della salute. Rapporto annuale sull'attività di ricovero ospedaliero (Dati SDO 2016, 2017. 
17 Billings J, Anderson GM, Newman LS. Recent findings on preventable hospitalizations. Health Aff 1996;15:239-49.

18 Mercier G, Georgescu V, Bousquet J. Geographic variation in potentially avoidable hospitalizations in France. Health Aff 2015;34:836-43.

19 Weeks WB, Ventelou B, Paraponaris A. Rates of admission for ambulatory care sensitive conditions in France in 2009-2010: trends, geographic variation, costs, and an international comparison. Eur J Health Econ 2016;17:453-70.

20 Casanova C, Starfield B. Hospitalizations of children and access to primary care: a cross-national comparison. Int J Health Serv 1995;25:283-94.

21 Parchman ML, Culler S. Primary care physicians and avoidable hospitalizations. J Fam Pract 1994;39:123-8.

22 Weissman JS, Gatsonis C, Epstein AM. Rates of avoidable hospitalization by insurance status in Massachusetts and Maryland. JAMA 1992;268:2388-94.

23 Billings J, Weinick RM. Monitoring the health care safety net: a data book for states and counties, 2003.

24 Gusmano MK, Strumpf E, Fiset-Laniel J, et al. Comparative analysis of health system performance in Montreal and new York: the importance of context for interpreting indicators. Health Econ Policy Law 2019;14:101-18.

25 Gusmano MK, Weisz D, Rodwin VG, et al. Disparities in access to health care in three French regions. Health Policy 2014;114:31-40.

26 Basu J, Friedman B, Burstin H. Primary care, HMO enrollment, and hospitalization for ambulatory care sensitive conditions: a new approach. Med Care 2002;40:1260-9.

27 Hossain MM, Laditka JN. Using hospitalization for ambulatory care sensitive conditions to measure access to primary health care: an application of spatial structural equation modeling. Int $\mathrm{J}$ Health Geogr 2009;8:51

28 Ansari Z, Haider SI, Ansari H, et al. Patient characteristics associated with hospitalisations for ambulatory care sensitive conditions in Victoria, Australia. BMC Health Serv Res 2012;12:475.

29 Lavoie JG, Wong ST, Ibrahim N, et al. Underutilized and undertheorized: the use of hospitalization for ambulatory care sensitive conditions for assessing the extent to which primary healthcare services are meeting needs in British Columbia first nation communities. BMC Health Serv Res 2019;19:50.

30 Vuik SI, Fontana G, Mayer E, et al. Do hospitalisations for ambulatory care sensitive conditions reflect low access to primary care? an observational cohort study of primary care usage prior to hospitalisation. BMJ Open 2017;7:e015704.

31 Paglione L, Migliara G, Di Paolo C, et al. Social determinants of avoidable hospitalizations for ambulatory care sensitive conditions. Eur J Public Health 2018;28:cky213. 215.

32 Rosano A, De Belvis AG, Sferrazza A. Trends in avoidable hospitalization rates in Italy, 2001-2008. Epidemiology biostatistics and public health 2013;10.

33 Louis DZ, Callahan CA, Robeson M, et al. Predicting risk of hospitalisation: a retrospective population-based analysis in a paediatric population in Emilia-Romagna, Italy. BMJ Open 2018;8:e019454.

34 Chau PH, Woo J, Gusmano MK, et al. Access to primary care in Hong Kong, greater London and new York City. Health Econ Policy Law 2013;8:95-109.

35 Abel G, Elliott MN. Identifying and quantifying variation between healthcare organisations and geographical regions: using mixedeffects models. BMJ Qual Saf 2019;28:1032-8.

36 OECD/European Observatory on Health Systems and Policy. Italy: country health profile 2017. OECD Publishing/ European Observatory on Health Systems and Policies, 2017.

37 Alcusky M, Singer D, Keith SW, et al. Evaluation of care processes and health care utilization in newly implemented medical homes in Italy: a population-based cross-sectional study. Am J Med Qual 2020;35:1062860619860590.

38 Bobini M, Cinelli G, Gugiatti A, et al. La struttura e le attività del SSN. In: Rapporto OASI 2019 Osservatorio sulle Aziende e sul Sistema sanitario Italiano. CERGAS - Bocconi ed, 2019.

39 Dalla Zuanna T, Cacciani L, Barbieri G, et al. Avoidable hospitalisation for diabetes mellitus among immigrants and natives: results from the Italian network for longitudinal metropolitan studies. Nutr Metab Cardiovasc Dis 2020;30:1535-43. 